\title{
Disability assessment of diabetic patients in Erbil city
}

\author{
Received: $6 / 4 / 2014$
}

Accepted: 2/6/2014

\begin{tabular}{rrr}
\hline Dara Abdulla Al-Banna * & Saadia Ahmed Khuder * \\
\hline & Abstract &
\end{tabular}

Background and objective: The disabling effects of diabetes mellitus are multi-factorial, which can result in the high prevalence of long term complications. The aim of this study was to assess disability levels of diabetic patients.

Methods: A quantitative design descriptive study was conducted in Leila Qasim Center in Erbil City in the Kurdistan Region of Iraq from February 2012 to February 2013. A non-probability purposive sample of 400 diabetic patients for more than 5 years was selected. A questionnaire was designed and divided into three parts: sociodemographic data, clinical data, and the standardized questionnaire developed by World Health Organization for disability assessment.

Results: The highest percentage $(57 \%)$ of diabetic patients had a moderate level of disability, while $23 \%$ had a mild level of disability. Severe level of disability was present in $20 \%$ of sample. No one had not disability or extreme level of disability.

Conclusion: More than half of diabetic patients were in the moderate level of disability. Keywords: Disability, Assessment, Diabetic patients.

\section{Introduction}

Diabetes Mellitus (DM) is one of the main threats to the human health in the $21^{\text {st }}$ century. It is the fourth to fifth leading cause of death in developed countries. ${ }^{1}$ The prevalence of diabetes is rising worldwide, and the Kurdistan Region of Iraq is no exception. The prevalence rate of diabetes in Erbil City in 2008 was 5-8\% based on estimation by the International Diabetes Federation. ${ }^{2}$ Currently, the director of the Media Department of Kurdistan's Health Ministry declares that in 2010 more than 100,000 peoples more women than men had diabetes in Kurdistan, and the prevalence of diabetes is accelerating, particularly in urbanized areas. ${ }^{3}$ Diabetes mellitus is highly prevalent among both sexes in the member states of the Eastern Mediterranean Region. Its prevalence ranges from between $3.5-30 \%$, and it is highest among the member countries of the Gulf Cooperation Council (GCC) (11.5-30.0\%). Many countries in the region are now reporting the onset of type
2 diabetes mellitus at an increasingly young age. This is due to increasingly sedentary lifestyles, higher life expectancy and obesity. ${ }^{4}$ In 2003, the five countries with the highest diabetes prevalence in the adult population were Nauru (30.2\%), United Arab Emirates (20.1\%), Qatar $(16 \%)$, Bahrain $(14.9 \%)$, and Kuwait $(12.8 \%) .^{5}$ Research has reveled that diabetic person has a greater prevalence of mobility disability and activities of daily living (ADL) disability. The risk of physical disability increases with age and can significantly impact the quality of life of older people. ${ }^{6}$ Chronic disease is one of the causes leading to disability. Overall risk of dying among people with diabetes is at least double the risk of their peers without diabetes. ${ }^{7}$ People with diabetes are much more likely to have physical limitations than those without diabetes. ${ }^{8}$ Diabetes prevalence increases sharply with age, and it is projected that by the year 2025, the majority of persons with diabetes will be aged 65 years or older. Although diabetes

* Department of nursing, college of nursing, Hawler medical university, Erbil, Iraq. 
is often accompanied by vascular and neuropathic co-morbidities, the threats of physical disability, loss of independence, and diminished quality of life may ultimately be the greatest concern for many with the disease. Cross-sectional data show that $50 \%$ of older people with diabetes report difficulty performing daily physical tasks, such as climbing stairs. ${ }^{9}$ Because diabetes prevalence rises with age, the impact of diabetes on disability is likely to be particularly significant in an aging population, where disability rates are known to be higher than in a younger population. ${ }^{10}$ Diabetes requires continuing medical and nursing care in order to prevent its acute complications and to reduce the risk of long term complications. Therefore, the nursing personnel are the first line step who can plan for the patients in advance how to control their disease to prevent developing disabilities, so they can live as normal as possible in carrying out their daily living activity. Diabetes is rapidly increasing in prevalence among adults, but little is known about the clinical characteristics that predict activities disability in this population. Therefore, the aim of this study was to assess the overall levels of disability of diabetic patients.

\section{Methods}

Research design: Cross-sectional study. Setting: Leila Qasim Center for Diabetes Care in Erbil City in the Kurdistan Region of Iraq.

Study sample: The population of this study was made of adult diabetic patients. A non probability, purposive sample selection was used in order to obtain the representative sample according to the following inclusion criteria: type 1 or type 2 diabetic patients, subjects agreement to participate in the study, age $\geq 18$ years, both genders, duration of disease five years and more, and good personal communication.

Sample size estimation: The sample size was calculated using the following statistical formula: ${ }^{11}$
Sample size $=Z^{2} \mathrm{pq} / \mathrm{d}^{2}$ where $Z=$ confident interval $95 \%$ (1.96), $p=$ prevalence $(0.08),{ }^{2} q=(1-p)=(0.92)$, and $d=$ sampling error $(0.05)$

Sample size $=(1.96)^{2}$ * $(0.08) *(0.92) /$ $(0.05)^{2}=113$

Notes: $(0.08)$ is the prevalence of diabetes mellitus in Kurdistan. ${ }^{2}$ The researchers recommended to select 400 cases as a sample size, to be more accurate representative sample.

Pilot study: A pilot study was carried out on ten patients to determine the reliability of the questionnaire. The pilot study samples were selected from the same setting. After 15 days the same sample was selected to ask the same items in the questionnaire.

Reliability of the questionnaire: The alpha correlation coefficient was computed, and the correlation was 0.885 , which was statistically adequate. For more assurance, after comparing between the results of these two samples through t-test, the difference indicated that it was nonsignificant $(P=0.21)$, which means that statistically it was adequate.

Ethical considerations: Before collecting the data, the researchers obtained approval of the Ethics Committee at the College of Nursing, Hawler Medical University. The official permission from the Ministry of Health in Erbil Directorate of Health and Leila Qasim Center for Diabetes Care in Erbil City was obtained. Informed consent of the study participants was obtained.

Data collection: Data were gathered through the use of a questionnaire. It was adapted from the WHO Disability Assessment Schedule Version II (WHODAS 2.0). Some modifications were made in the items and the sociodemographic data, and the clinical data were added to the original questionnaire. Data were collected through direct interview with the participants during the period of May $5^{\text {th }}, 2012$ to July $18^{\text {th }}$, 2012. The average time spent with each client was 20-25 minutes. For assessing the disability level, the questionnaire was 
used as a means of data collection and it consists of three main parts. A special scale which was developed by WHO was used. It is designed to be applicable across different cultures, in all adult populations, and it treats all disorders at parity when determining the level of functioning. The questionnaire contains 36 items of Likert formatted questions on functioning and disability, divided in to six main domains. The response options range from 1 (no difficulty), 2 (mild difficulty), 3 (moderate difficulty), 4 (severe difficulty), to 5 (extreme difficulty or cannot do). ${ }^{12}$

Design of questionnaire:

Part I: Sociodemographic data: Includes the general information about diabetic patient (age, gender, years of education, marital status, occupational status, and residential area).

Part II: Clinical data: Includes the data about the medical or clinical information of the diabetic patient, such as duration of diabetes mellitus according to clinical patient's file.

Part III: Disability assessment data:

Consists of a questionnaire scale of the World Health Organization Disability Assessment Schedule II (WHODAS 2.0). Scoring of scales: The scoring of the full version of WHODAS 2.0 takes into account the paid-work status of the respondent, with 32 items (one item omitted) being used if the respondent is not in gainful employment. The more complex method of scoring is "item-response-theory" (IRT) based scoring which takes into account multiple levels of difficulty for each WHODAS 2.0 item. It takes the coding for each item response as "none", "mild", "moderate", "severe" and "extreme" separately, and then uses a computer to determine the summary score by differentially weighting the items and the levels of severity.

Overall level of disability (32 items) = Domain $1+$ Domain $2+$ Domain $3+$ Domain 4 + Domain 5A + Domain 6 .

Overall level of disability (36 items) = Domain $1+$ Domain $2+$ Domain $3+$
Domain $4+$ Domain $5 \mathrm{~A}+$ Domain $5 \mathrm{~B}+$ Domain 6.

Rating the percentage scores into five levels of disability between 0 to100 (where $0=$ no disability; 100 = full disability) according to the International Classification of Functioning, disability, and health (ICF) as following: None (0-4 \%), Mild (5-24 \%), Moderate (25-49\%), Severe (50-95\%), and Complete or extreme (96-100\%).

Note: WHODAS 2.0 aims to reflect the key features of the ICF. It has been designed to assess the limitations on activity and restrictions on participation experienced by an individual, irrespective of clinical diagnosis. ${ }^{12}$ WHODAS 2.0, 36 items over six domains with the corresponding International Classification of Functioning, Disability and Health (ICF) codes. $^{13}$

Data management and statistical analysis: The data were analyzed through the statistical package for the social sciences (version18).

1- Descriptive data analyses: Includes the frequency, percentage, mean, and standard deviation measurements.

2- Inferential statistical data analysis: Includes pearson coefficient correlation (r-test): If $r=( \pm 1)$ =Perfect, $( \pm 0.75-$ $\pm 1)=$ Strong, $( \pm 0.5- \pm 0.75)=$ Moderate, $(<0.5)=$ Weak, $(0)=$ no linear association. ${ }^{14}$ Chi-square test was used for comparing proportions. A $P$ value of $\leq 0.05$ was considered statistically significant.

\section{Results}

\section{Sociodemographic characteristics of diabetic patients}

Table 1 shows the following characteristics of the sample regarding to the sociodemographic information: The highest percentage of the sample $(47.8 \%)$ was in the age group 50 - 64 years old, while the lowest percentage $(2.5 \%)$ was 20 - 34 years old, with the mean age of 52.4 years old. With regard to the gender, the majority of the sample $(70 \%)$ were female and the minority were male $(30 \%)$. The level of education indicates that the majority 
of the subjects were illiterate $(85.7 \%)$ and the minority $(2 \%)$ had $\geq 13$ years of education. Majority were currently married $(87 \%)$, widowed $(11 \%)$, never married $(2 \%)$, and none were separated and divorced. Concerning the occupational status of the sample, the majority of the sample $(67.5 \%)$ were keeping house or homemaker, the remaining participants were unemployed for other reason $(17.5 \%), \quad 9 \%$ had paid work, $6 \%$ were retired, and none $(0 \%)$ were self employed, in non-paid work, student; and unemployed for health reason. With regard to the residential area, the highest percentage of the sample $(68.7 \%)$ was from urban and $31.3 \%$ was from rural area.

Table 1: Sociodemographic characteristics of diabetic patients.

\begin{tabular}{|c|c|c|c|}
\hline \multicolumn{2}{|c|}{ Sociodemographic characteristics } & \multicolumn{2}{|l|}{$n=400$} \\
\hline & & $\mathbf{F}$ & $\%$ \\
\hline $\begin{array}{l}\text { Age } \\
\text { (years) }\end{array}$ & $\begin{array}{l}20-34 \\
35-49 \\
50-64 \\
65-79 \\
\text { Total } \\
\text { M } \pm \text { SD }\end{array}$ & $\begin{array}{l}10 \\
140 \\
191 \\
59 \\
\mathbf{4 0 0} \\
\mathbf{5 2 . 4} \pm \mathbf{9 . 8}\end{array}$ & $\begin{array}{l}2.5 \\
35 \\
47.8 \\
14.7 \\
100\end{array}$ \\
\hline Gender & $\begin{array}{l}\text { Male } \\
\text { Female } \\
\text { Total }\end{array}$ & $\begin{array}{l}120 \\
280 \\
400\end{array}$ & $\begin{array}{l}30 \\
70 \\
100\end{array}$ \\
\hline $\begin{array}{l}\text { Educational level } \\
\text { (years) }\end{array}$ & $\begin{array}{l}0 \text { (Illiterate) } \\
1-6 \\
7-12 \\
\geq 13 \\
\text { Total }\end{array}$ & $\begin{array}{l}343 \\
33 \\
16 \\
8 \\
\mathbf{4 0 0}\end{array}$ & $\begin{array}{l}85.7 \\
8.3 \\
4 \\
2 \\
100\end{array}$ \\
\hline Marital status & $\begin{array}{l}\text { Never married } \\
\text { Currently married } \\
\text { Separated } \\
\text { Divorced } \\
\text { Widowed } \\
\text { Total }\end{array}$ & $\begin{array}{l}8 \\
348 \\
0 \\
0 \\
44 \\
400\end{array}$ & $\begin{array}{l}2 \\
87 \\
0 \\
0 \\
11 \\
100\end{array}$ \\
\hline Occupational status & $\begin{array}{l}\text { Paid work } \\
\text { Self employed } \\
\text { Non-paid work } \\
\text { Student }\end{array}$ & $\begin{array}{l}36 \\
0 \\
0 \\
0\end{array}$ & $\begin{array}{l}9 \\
0 \\
0 \\
0\end{array}$ \\
\hline & $\begin{array}{l}\text { Keeping house/homemaker } \\
\text { Retired } \\
\text { Unemployed (health reason) } \\
\text { Unemployed (other reason) } \\
\text { Total }\end{array}$ & $\begin{array}{l}270 \\
24 \\
0 \\
70 \\
400\end{array}$ & $\begin{array}{l}67.5 \\
6 \\
0 \\
17.5 \\
100\end{array}$ \\
\hline Residential area & $\begin{array}{l}\text { Urban } \\
\text { Rural } \\
\text { Total }\end{array}$ & $\begin{array}{l}275 \\
125 \\
\mathbf{4 0 0}\end{array}$ & $\begin{array}{l}68.7 \\
31.3 \\
100\end{array}$ \\
\hline
\end{tabular}


2. Clinical characteristics of diabetic patients: Table 2 shows the distribution of the sample according to the clinical characteristics. In relation to the duration of diabetes mellitus by years, the highest percentage $(83 \%)$ of the sample in durations of diabetes mellitus was $5-13$ years, while the lowest percentage $(0.3 \%)$ was 32 - 40 years, with the mean duration of 9.65 years.
3. Levels of disability of diabetic patients

Table 3 shows the levels of disability among 400 diabetic patients. The highest percentage $(57 \%)$ of diabetic patients had a moderate level of disability. 23\% had a mild level of disability. Severe level of disability was present in $20 \%$ of sample, and $0 \%$ of sample had none and extreme level of disability.

Table 2: Clinical characteristic of diabetic patients

\begin{tabular}{llc}
\hline $\begin{array}{l}\text { Clinical characteristic } \\
\text { Duration of DM / years }\end{array}$ & $\mathbf{n}=\mathbf{4 0 0}$ & $\%$ \\
\hline $5-13$ & 332 & 83 \\
$14-22$ & 49 & 12.2 \\
$23-31$ & 18 & 4.5 \\
$32-40$ & 1 & 0.3 \\
Total & $\mathbf{4 0 0}$ & $\mathbf{1 0 0}$ \\
& $\mathbf{M} \pm \mathbf{S D}=\mathbf{9 . 6 5 \pm \mathbf { 5 . 6 }}$ \\
\hline
\end{tabular}

Table 3: Levels of disability of diabetic patients

\begin{tabular}{lll}
\hline Levels of disability (percentage score) & F & $\%$ \\
\hline None $(0-4) \%$ & 0 & 0 \\
Mild $\quad(5-24) \%$ & 92 & 23 \\
Moderate (25-49) \% & 228 & 57 \\
Severe (50-95) \% & 80 & 20 \\
Extreme or cannot do (96-100) \% & 0 & 0 \\
Total & 400 & 100 \\
\hline
\end{tabular}




\section{Discussion}

Because diabetes prevalence rises with age, the impact of diabetes on disability is likely to be particularly significant in an aging population. Around $48 \%$ of the study samples' age was from 50-64 years old. This finding is similar to the results that the prevalence of diabetes increases with age. ${ }^{16}$ Supported with the results of the study who found that the mean age of the diabetic patients were 53.3 years old, ${ }^{17}$ the mean age in the present study was 52.4 years old. Thus research indicated that the incidence of diabetes is higher in elderly people and the mean age of them was 55 years old. ${ }^{18}$ The percentage of the prevalence of the diabetes increased with age $(7.5 \%$ in $50-54$ years old vs. $0.3 \%$ in 18-29 years old). ${ }^{19}$ This result approved that the risk of diabetes increased with the progressing of age. However, the present study showed that the numbers of diabetic persons attending diabetic clinic from the age 65-79 years old were less in comparing to the earlier aging group from 50-64 years old. The reason of this shortage numbers among the previous aging group may be some of them unable to see their physician either due to diabetes complications, lost of the life or the aging process preventing them to see their physician regularly. In addition majority of them are illiterate and unable to recognize the danger of uncontroling their disease on the future life, furthermore, more than two third of the study sample was female and married usually most of them are housewife may be unable to leave the house responsibilities. Gender is a variable found in the present study that the majority of the study sample was female. A study reported that there was a significant effect of gender with diabetes and they stated that the women were more likely to have diabetes mellitus than men. ${ }^{20} \mathrm{~A}$ four annual survey done in USA to identify cases in general population and as a base line survey to follow disease progression in individuals with an established diagnoses of the disease, it found that more than half of these individuals with diabetes were female. ${ }^{21}$ Another study recently conducted in Duhok in Kurdistan Region of Iraq found that the prevalence of diabetes in female was $15.2 \%$ compared to $11.8 \%$ in males. ${ }^{22}$ From all these results we can understood that the disease is higher in female than male as a general. This can be due to many reasons one of them is the women are expose to many physiological changes as in pregnancy that might be affected the action of the hormone responsible for this disease. Analysis of the present study showed that the majority of the study sample was illiterate and supported with the studies done in 2011 and 2007. ${ }^{23,17}$ Regarding level of education, the present research indicated that there is association between level of education and the prevalence of the disease. It has been shown that the knowledgeable persons are more able to follow the regime plan regarding diet, exercise, monitoring test, and treatments. ${ }^{24}$ The current study reported that the majority of the study sample was unemployed due to their disease as well as most of them were female and in an advanced age group, which is similar with the prospective occupational cohort study who revealed that the person working in the lower employment grades had a higher incidence of diabetes than those in higher employment grades. This is explaining that the economic factors contributed in the developing of the disease indirectly because low financial status person cannot afford to follow the planed diet. ${ }^{25}$ This study is contradicted to the study done at Iran, they found that $4.1 \%$ were employed only. Comparing to the present study that $41 \%$ of males and $38 \%$ of females were employed, this is impressing in comparing to the previous study, here the participant may be better controlling the disease or may be the duration of the disease is not for long period of time, therefore not yet develop the apparent complication, so the participant can work as much as possible. The higher participants of the present 
study were from urban area this is may be due to availability of transportation, financially higher, and more knowledgeable than rural residency. This result disagreed with the studies conducted in Egypt ${ }^{26}$ and Bangladesh, ${ }^{27}$ they reveled that the prevalence of the disease is higher in rural area than urban. This may be due to the life style and mainly diet habits in Kurdistan Region the rural population usually are more vegetarian than the urban area. While a study in 2001 reported that the prevalence of diabetes was not related to the area of living. ${ }^{15}$ In relation to the duration of disease in the current study, $83 \%$ of the sample had the disease from $5-13$ years and $0.3 \%$ had the disease from $32-40$ years. The reason behind this results in the second group may be due to developing complications of the disease, which prevent them to attend the center, it has been reported that the longer duration the disease the more developing complications. The result is going along with the study done in Pakistan, in 2012, showing that $62 \%$ of the study sample had the disease for 6-15 years. ${ }^{28}$ This agrees with a retrospective, cross-sectional study done in China which found the mean duration of the disease among the sample was 8.05 years. ${ }^{29}$ Regarding the level of disability among the present study, more than half of the sample had disability at the level of moderate. Several studies have shown that the patients with diabetes have greater impairments in mobility and more difficulties in performing basic activities of daily living than similarly aged non-diabetic people. $^{30}$ Individuals with diabetes at increased risk of functional disability miss more days from work for health reasons, and have reduced earnings from employment. Results from several studies have indicated that diabetes complications are associated with increased work disability. ${ }^{31}$

\section{Conclusion}

The study showed that most of the study samples were elderly with mean age of
52.4 years old and the majority were female, illiterate, married, with keeping house occupation from urban area. Most of the participants have had diabetes for $5-13$ years, and more than half of diabetic patients were in the moderate level of disability.

\section{Conflicts of interest}

The author reports no conflicts of interest.

\section{References}

1. Tripathi BK, Srivastava AK. Diabetes mellitus: Complications and therapeutics. Med Sci Monit 2006; 12(7):130-47.

2. Kakel D, Khoshnaw H, Albustany DA. Report on a center for diabetes care in Hawler in Kurdistan Region. Erbil; 2008. (Accessed February 21, 2012 at www.kuma.org.uk).

3. Dooski E. Rising rates of diabetes in Kurdistan a cause for concern. Kurdish globe 2011. (Accessed October 28, 2012 at http:// www.kurdishglobe. net/display article.html? id=2727C389F2E01EE69789 19CE5C9E39A).

4. Rathmann W, Giani G. Global Prevalence of Diabetes: Estimates for the Year 2000 and Projections for 2030. Diabetes Care 2004; 27 (10):2568-9.

5. International Diabetes Federation. Diabetes Atlas. $15^{\text {th }}$ ed, Brussels; 2011. (Accessed November 9, 2012 at http://www.idf.org/diabetesatlas/ ).

6. Al Snih S, Fisher M, Raji M, Markides K, Ostir G, Goodwin J. Diabetes Mellitus and Incidence of Lower Body Disability among Older Mexican Americans. J Gerontol A Biol Sci Med Sci 2005; 60(9):1152-6.

7. Gibson Ph. Definition of Disability. England. Northern Ireland; 2007. P. 3-4.

8. Ryerson B, Tierney E, Thompson T, Engelgau M, Wang J, Gregg E, et al. Excess Physical Limitations among Adults with Diabetes in the U.S. Population. Diabetes Care 2003; 26(1): 206-10.

9. Gregg E, Mangione C, Cauley J, Thompson T, Schwartz A, Ensrud $K$, et al. Diabetes and Incidence of Functional Disability in Older Women. Diabetes Care 2002; 25(1):61-7.

10. Maty S, Fried L, Volpato S, Williamson J, Brancati F, Blaum C. Patterns of disability related to diabetes mellitus in older women. J Gerontol A Biol Sci Med Sci 2004; 59(2):148-53.

11. Araoye MO. Research Methodology with Statistics for Health and Social science. Nigeria: Nathadex publisher Irion; 2003. $1^{\text {st }}$ ed. P. 118-9.

12. World Health Organization. World report on disability. Switzerland: Publications of the WHO; 2011. (Accessed April 18, 2012 at www.who.int/disabilities/world_report/2011/en/ index.html). 
13. Ustün $\mathrm{T}$, Chatterji $\mathrm{B}$, Kostanjsek $\mathrm{N}$, Rehm J, Kennedy C, Jordan J, et al. Developing the World Health Organization Disability Assessment Schedule 2.0. Bull World Health Organ. 2010; 88 (11):815-23.

14. Ellison $S$, Barwick $V$, Farrant T. PEARSON'S R, CHI-SQUARE, T-TEST, AND ANOVA, Practical Statistics for the Analytical Scientist. $1^{\text {st }}$ ed. Cambridge: Royal Society of Chemistry; 2008. P. 120-4.

15. Motulsky $\mathrm{H}$. Intuitive Biostatistics: A Nonmathematical Guide to Statistical Thinking. $2^{\text {nd }}$ ed. USA: Oxford University Press; 2010.

16. Choi BC, Shi F. Risk factors for diabetes mellitus by age and sex: results of the National Population Health Survey. Diabetologia 2001; 44(10): 1221-31.

17. Al-Maskari F, El-Sadig M. Prevalence of diabetic retinopathy in the United Arab Emirates. BMC Ophthalmology 2007;7(11).

18. Mansour AA. Chronic Complications of Diabetes in Iraq: Experience from Southern Iraq. Clin Med Insights Endocrinol Diabetes; 2009(2):89-97.

19. Corsi DJ, Subramanian SV. Association between socio-economic status and self-reported diabetes in India. BMJ OPEN 2012; 2(e000895). (Accessed November 26, 2012 at http://bmjopen.bmj.com/).

20. Ovbiagele B, Markovi D, Fonarow G. Recent US Patterns and Predictors of Prevalent Diabetes among Acute Myocardial Infarction Patients. Cardiology Research and Practice. 2011; 2011 (145615).

21. Rodbard H, Green A, Fox K, Grandy S. Trends in Method of Diagnosis of Type 2 Diabetes Mellitus. Int J Endocrinol ; 2009(796206).

22. Abdulrahman MA. Risk Factors Survey for Non-Communicable Diseases in Duhok City. Duhok Med J 2010; 4(2): 69-83.

23. Agardh E, Allebeck P, Hallqvist J, Moradi T, Sidorchuk1 A. Type 2 diabetes incidence and socio-economic position. Oxford University Press 2011; 2011(40):804-18.

24. American Diabetes Association. Standards of Medical Care for Patients with Diabetes Mellitus. Diabetes Care 2003; 26(1):533-50.

25. Kumari M, Head J, Marmot M. Social and Other Risk Factors for Incidence of Type 2 Diabetes in the Whitehall II Study Free. Arch Intern Med 2004; 164(17):1873-80.

26. Arafa NSh, Amin GhE. The Epidemiology of Diabetes Mellitus in Egypt: Results of a National Survey. The Egyptian Journal of Community Medicine 2010; 28(3):29-43.

27. Akhter A, Fatema K, Afroz A, Bhowmik B, Ali L, Hussain A. Prevalence of Diabetes Mellitus and its Associated Risk Indicators in a Rural Bangladeshi Population. Open Diabetes J 2011; 4:6-13.

28. Shaikh MKh, Devrajani BR, Shaikh A, Ali-Shah SZ, Shaikh S, Singh D. Plasma Homocysteine Level in Patients with Diabetes mellitus. World Appl Sci J; 16(9):1269-73.
29. He B, Wei L, Gu Y, Han J, Li M, Liu Y, et al. Factors Associated with Diabetic Retinopathy in Chinese Patients with Type 2 Diabetes Mellitus. Int J Endocrinol; 2012 (2012) ID 157940.

30. Bruce DG. Type 2 diabetes mellitus and disability. U.S.: Center for International Rehabilitation Research Information and Exchange, 2010. (Accessed April 27, 2012 at cirrie.buffalo.edu/encyclopedia/en/article/289/).

31. Korff M, Katon W, Lin E, Simon G, Ciechanowski P, Ludman E, et al. Work Disability among Individuals with Diabetes. Diabetes Care 2005; 28(6):1326-32. 